\title{
The Neolithic ceremonial complex at Niuheliang and wider Hongshan landscapes in North-eastern China
}

\author{
Hai Zhang ${ }^{1}$, Andrew Bevan², and Dashun Guo ${ }^{3}$ \\ Postprint of paper in Journal of World Prehistory.
}

\begin{abstract}
This paper reviews the current evidence for settlement patterns and ceremonial activity amongst Hongshan Neolithic groups in north-eastern China, with particular attention to the well-known ceremonial site at Niuheliang. In particular, we consider the locational properties of Hongshan ceremonial sites in their wider landscape settings, arguing that such sites are a chronologically late stage of Hongshan ceremonial investment and that, within these broad complexes, the most impressive architecture and portable goods come from an especially late phase of activity. These more impressive localities were also particularly privileged places in terms of their access to major routes through the landscape, specific kinds of local geology and integrated patterns of visibility. In contrast to more loosely organized, similarlysized Hongshan residential sites, it is clear that ceremonial centres such as Niuheliang (and, within these, certain important sub-localities) were key mechanisms for social, political and regional stratification around roughly the mid 6th millennium BP.
\end{abstract}

Keywords: Hongshan, sacred landscapes, site location models, viewsheds, GIS

\section{Introduction}

Archaeological discoveries over the past two decades have made it very clear that a range of otherwise culturally distinct Neolithic societies across China undergo significant social and economic changes starting from about the mid $6^{\text {th }}$ millennium BP. For example, apparent public structures and elaborate residences have been found in Late Yangshao period settlements in central China, while finely-decorated pottery forms and carved jade artefacts probably indicate elite burials at the Dawenkou, Lingjiatan and Songze cemeteries in eastern China. While it would be

\footnotetext{
${ }^{1}$ School of Archaeology and Museology, Peking University, Beijing 100871, China. email: haizhang@pku.edu.cn

${ }^{2}$ Institute of Archaeology, University College London, 31-34 Gordon Square, London WC1H 0PY, United Kingdom email: a.bevan@ucl.ac.uk

${ }^{3}$ Liaoning Provincial Institute of Cultural Relics and Archaeology, Shenyang 110003, China.
} 
inappropriate to link the emergence of these regional Neolithic cultures with much later patterns of Chinese political unification, they are nonetheless the first observable developments towards considerably more complex societies in each of these sub-regions of China (Su 1997). In fact, comparably striking social changes can also been attested in northeast China from about the same period, and this paper focuses on the ritual and settlement landscapes of these Hongshan communities which some have argued made important cultural contributions to the form and emphasis of later Chinese civilisation (Figure 1). In particular, we consider patterns of settlement and ceremonial activity amongst these Hongshan groups, with special attention to the well-known ceremonial site at Niuheliang. Our main goal here is to consider the relationship between settled and ceremonial landscapes and, via a combination of updated archaeological evidence and spatial modelling, to unpick patterning at Niuheliang itself more carefully.

\section{Hongshan Settlement and Ceremonial Sites}

Neolithic Hongshan culture was first characterised early in the 1900s and many archaeological excavations and surveys have been devoted to its investigation since then. Archaeologically, the most well-known and diagnostic Hongshan artefacts are red painted or Z-striped ceramics, jade objects and certain multiform stone tools. Most Hongshan sites date to between ca.6,500 and 5,000 B.P. and are found across western Liaoning province and the southeastern part of Inner Mongolia, thus covering a variety of landscapes, including the mountain ranges stretching from northwest to southeast, but also the lower hill country to either side, various river valley systems, areas of arid desert to the north, the Bohai embayment in south and a large floodplain created by the lower Liao River in the east (Figure 2; Guo 2005:134).

There are two well-known types of site associated with the Hongshan period: settlements and so-called ceremonial centres. Most of the settlements are located in river valleys created by the upper Liao River, Daling River and their branches. Other settlement evidence has even been found in desert areas or in caves, but as yet only occasionally in the large eastern floodplain (Guo 2005: 25-29), perhaps due to geomorphological factors. Some of our information about settlement sites comes from chance discoveries, and hence is only of limited analytical use with respect to overall regional patterning, but in addition, several systematic surveys and a few more detailed archaeological excavations provide deeper insights at several interpretative scales. Systematic regional surveys in the Hongshan area have used well-established, intensive or moderately intensive methods (e.g. explicitly covered sub-areas, systematic line-walking in some cases, and/or formal surface collections), particularly within several river valleys, to explore community-level organisation and possible Hongshan demographic patterns (CICARP 2003; IMAT and MAB 2005; Peterson et al. 2010). 
Despite this level of attention and fairly consistent archaeological retrieval, further problems relate to palimpsest remains covering both Hongshan and later periods, as well as to the persistence of different kinds of methods for estimating variables such as site size, which makes comparison between survey projects more difficult. Even so, some general observations are possible. The vast majority of sites are small (expressing themselves as only a few hectares of surface scatter) and where excavated, produce no thick cultural deposits. This sits in contrast to Neolithic sites found in central China, along Yellow and Yangtze rivers, at this time and suggests shorter-term occupations. In addition, there do seem to be a few rare examples of larger sites (e.g. >10 ha) that may indicate either a few bigger communities, perhaps of dozens of families each, or otherwise unusual patterns of occupation. Excavations of a few sites have revealed Hongshan houses that were often semi-subterranean and built in circular or square shapes, with timber frames and daub walls. The footprint of these houses is generally $20-30 \mathrm{~m}^{2}$, with only a few reaching up to 100 $\mathrm{m}^{2}$ (IMAT 1982; IMPICRA 1994; 2004). A limited number of studies dedicated to plant and animal remains suggest a mixed household economy based on millet cultivation, wild food collection, pig husbandry and deer hunting which suggests exploitation of a variety of local landscapes (Guo and Ma 1985; Zhao 2005).

Although most people seem to have lived in small, potentially short-lived, villages, in partially-sunken dwellings, it can be argued that Hongshan settlements were also part of both local and regional aggregations comprising many smaller sites each. For example, at a coarse regional scale, more than 500 Hongshan sites have been identified within the ca.8,000 sq.km of Aohan district alone, which greatly exceeds the densities recorded for other Neolithic societies in China by similar field methods. Part of the explanation for this dense aggregation no doubt relates to greater archaeological attention to this district, but it also probably suggests at least one, if not one of several, core regions of higher density activity (Shao 1995). At a finer local scale, spatial analysis of the regional survey data from lower of Bang River, Chifeng and Dongshanzui indicate that the Hongshan sites were loosely grouped into clusters spanning 2 to $8 \mathrm{~km}^{2}$ each (CICARP 2003; IMAT and MAB 2005; Peterson et al. 2010). However, despite the presence of these aggregations, it remains unclear whether we really should understand these as larger-scale political or economic entities, and if so, how such integration was organised given the strong contrasts with other contemporary Chinese Neolithic cultures. The reinvestigation of ceremonial sites offered below may provide further insight on these issues, by considering questions of location in the landscape, logistical organisation and changing investment through time.

Hongshan ceremonial sites are also found in larger clusters of discrete localities. Ceremonial aggregations or centres of this kind include Niuheliang (牛河梁), Dongshanzui (东山嘴), Sijiazi (四家子) and Hutougou (胡头沟) amongst others (CBCC and LPICRA 2004; Guo and Zhang 1984; Shao 2004; Fang and Liu 1984), and are famous for their burials with jade artefacts and elaborate architectural additions. So far, more than 90 burials have been excavated at such centres, and at 
least 70 can be dated to approximately the same phase as Niuheliang (Huan and Yang 1998: 35). The burials all typically involve grave pits cut vertically into the earth surface and built with slabs of limestone, whose borders were often surrounded by painted pottery cylinders of uncertain function. The offerings in these burials were mainly made from jade river pebbles suggesting much secondary access to this material rather than acquisition for primary outcrops. A further kind of monumental architecture involves circular or square-shaped altars of different sizes, often appears together with these burial groups and may conceivably have been used for associated funerary ceremonies. In addition, at the site of Niuheliang, a semi-subterranean building, popularly known as the "Goddess Temple", was unearthed, containing many ceramic nude female statues in different sizes (LPICRA 1986, and see below). The range of features at these ceremonial sites are one clear indication that the communities that produced them were able: a) to mobilise substantial labour to build these constructions and b) to develop the specialist crafting skills necessary to produce the jade carvings and painted, non-utilitarian ceramic forms. It is also obvious that the burials at these ceremonial sites cannot represent all segments of Hongshan society and that they were probably places for the interment of social, political and/or religious elites of some kind.

The known aggregations of ceremonial sites are mainly located on the southwestern edge of the known Hongshan settlement region. In most cases, they are found separated from the core zones of settlement, with Dongshanzui being the only probable exception to this rule. ${ }^{4}$ Moreover, comparing their individual locations to those of Hongshan settlements, the former are more likely to be placed on low hills in front of mountains which, as we argue more formally below, provided a specific kind of environmental context whose meaning could be manipulated and enhanced in a variety of ways. In particular, the visual affordances (in the sense of Gibson 1986; see also Llobera 2001) offered at these ceremonials sites have already been emphasised by other commentators for some time, with respect to the proposed symbolic meanings of certain mountains, to patterns of inter-visibility and alignment among sites (CBCC and LPICRA 2004). We reconsider some of these issues below, but it is worth simply noting at this point that such carefully selected, well-appointed ceremonial areas do appear to have been of great importance as sacred places with the potential to integrate more scattered Hongshan settled communities.

\footnotetext{
${ }^{4}$ At Dongshanzui, survey has certainly documented a combination of settlement and ceremonial remains in the same area (LPICRA et al. 2010; Peterson et al. 2010). While there are as yet no published absolute dates or artefact assemblages to suggest one way or another, in our view it is worth at least considering the possibility that this site represents a palimpsest of different phases of activity within the longer Hongshan period, and that the settlement and ceremonial evidence may not be contemporary. Regardless, given this different pattern, it is clearly worth investigating further and Dongshanzui is discussed in a separate section below.
} 


\section{Niuheliang}

\subsection{Background}

Niuheliang comprises a loose group of individual sites that are best thought of as a whole landscape of Hongshan ceremonial activity spread out over a series of separate low hills in western Liaoning province. The Niuheliang complex of sites was first explored in the 1980s and consists of 16 main sites (LPICRA 1986; 1997a; 1997b; 1997c; 2001; 2008a; 2008b; Li 1986; Wei 1994), with another 26 smaller sites identified in the same vicinity during a recent full coverage survey project (Guo 2010a; Figure 3). Together, these sites include: a) over a dozen tomb groups, b) several stone-set circular compounds and square altars, and c) a large, irregularly shaped and partially sunken building known today as the "Goddess Temple". The finds from these areas are exceptionally rich by Chinese Neolithic standards, with a wide range of jade objects, unusual decorated pottery forms and life-sized or larger clay statuary.

Considering each of these three types of archaeological feature in turn, the tombs are rectangular and partially cut through into the local bedrock. The biggest is as much as 4 meters in length and width, and some of the larger tombs are cut almost 5 meters deep into the hard bedrock. They often have a stepped interior, edged with large limestone blocks and interior walls built with unbonded stacks of flat limestone pieces. Along the borders of many of the tombs were placed open-ended pottery cylinders with painted decoration. Offerings in the tombs were mainly jade objects in different shape, such as bracelets, cuffs, ear ornaments, animal-shaped themes and human figurines. (Figure $4 a-b$ )

The altars with flat or round top platforms, most of which are stepped buildings with rammed earth insides and stone-set walls outsides, have been suggested as central places for the practice of ceremonies. Some of them were built with red igneous rocks instead of the more popular white limestone of the surrounding buildings, which would undoubtedly have made them visually distinct from their surroundings. A large pyramid-shaped building (site no. 13) extends over some 100 meters in length at the base and is preserved up to 7 meters in height. It was placed at a further location separate from the tomb groups, but in terms of its design, it is similar to altars at tomb sites and might conceivably be regarded as another bigger form of altar set apart from the rest. (Figure 5a-b)

Finally, the so-called sunken building, or "Goddess Temple", has clay plastered walls, and some of them are painted in red with geometric designs. The roof was probably arch-shaped, made with woven branches and clay, and with a dense decoration in embossed clay. A great number of ceramic statues have been recovered from this building, including many different-sized broken nude female figurines and some animal figures such as dragons, boars and hawks (LPICRA 1986) (Figure 6a-b). A large platform in $40,000 \mathrm{~m}^{2}$ is located just behind the "Goddess Temple" with surrounded by a stone enclosure wall. At least three altars have been founded on 
this platform and some particularly large pottery vessels with bases up to $1 \mathrm{~m}$ in diameter, probably incense burners, were discovered at the same time (Hua 1994). The combination of this platform with its group of altars and the "Goddess Temple", both in one place, undoubtedly indicates the primary importance of this location (site no. 1) in the ceremonial activities of the entire Niuheliang complex of sites.

\subsection{Chronology}

It is now clear that not all the sites at Niuheliang were occupied simultaneously. Although the number of existing radiocarbon dates for Hongshan period sites is limited, recalibration of three from Niuheliang and one from Dongshanzui suggests (IACASS 1991:67,76; Figure 7) the possibility of a span of occupation over several hundred years, but places this at the end of the overall Hongshan period (e.g. clearly much later than those from settlement excavations at Xinglongwa; IACASS 1991:67,76; Figure 7). Typological studies of Hongshan pottery also suggest two or three sub-phases of Hongshan culture, with the Niuheliang sites probably dating to the last of these (Zhang 1991; Yang 1994; Zhang and Zhu 1994; Suo and Li 2007).

A final important, but more tentative chronological point is that excavations at certain sites within the Niuheliang complex seem to suggest a stratigraphic distinction between two discrete phases of tomb-building - known as the lower and upper burial deposits - although both belong to the Late Hongshan phase (LPICRA 1997b; Li 1986; Suo and Li 2007). The tombs buried in the lower deposits are comparatively small and at these, open-ended pottery cylinders were placed in a ring around each tomb, with a great deal of broken rock filling inside. The central graves were rectangular with walls of flat limestone slabs, but without any stone ledges or beds. These graves usually have a north-south orientation and most of the offerings are painted pottery cylinders (present at all such sites) or decorated urns with lids.

In contrast, the built features of the tombs in the upper deposits are very different. Burial pits are now wholly covered with limestone slabs including ledges and beds, and the orientation is primarily east-west. Piled up mounds of stones, including some large blocks, are sometimes found above such graves with painted pottery cylinders placed around the mound edges. The offerings within these seemingly later tombs are also entirely made of jade rather than pottery.

This apparent change in the character of tombs between lower and upper deposits ideally requires further confirmation via more explicit stratigraphic demonstration on a case-by-case basis and further absolute dates, but seems likely on present evidence, and is important for our understanding of the development of the Niuheliang ceremonial complex through time. Painted pottery cylinders, which can be easily found in each individual locality at Niuheliang, also have observable differences in shape over this proposed timescale. Therefore, and of relevance more generally at Hongshan ceremonial sites, we argue that stylistic variation in cylinder sherds is a useful chronological indicator even for surface remains. Based on this 
information, we can suggest more comprehensively that: a) most of the altars were built during the upper deposits period and are only present at larger sites, b) the construction of the "Goddess Temple" may fall in between the lower and upper deposits periods, c) large tombs are only found in the upper deposits period and only at those sites with many smaller surrounding tombs.

All of this evidence indicates that, sites in the Niuheliang area did not start to be used at the same time There were significant changes in the development of the Niuheliang sacred landscape and in the upper deposits period, class differentiation between sites becomes more obvious. The combination of tombs, altars and temples for ceremonial activities can only be found at larger sites. Meanwhile, there are also differences in the location of large versus small sites at Niuheliang, which will be further discussed below.

\subsection{Locational Patterns and the Material Landscape}

The Niuheliang sites are found in a landscape that is typical of the hilly lands in the valleys of upper Daling River, surrounded by mountains stretching from west Liaoning in the south to the western edge of the Hongshan zone. We begin from an assumption that the locations chosen for these sites are likely to have been promoted in some way by the demands of the ceremonial activities conducted there. Intuitively, and prior to the more formal analysis offered below, it seems as if shallow ridge-tops of low hills close to the river valley were a preferred environment (the modern placename of Niuheliang itself means Ox River Ridge in Chinese), perhaps because these localities were well-drained and afforded good visual connections with others in the vicinity.

In addition, a great deal of labour, probably drawn from several Hongshan communities was mobilised to build the tombs and associated ritual architecture, as well as to transport certain exotic building and burial materials from outside of the region (Yan 2006). For example, some 30 cubic metres of gneiss bedrock for one tomb at site 16 (LPICRA 2008b:9) was excavated with stone tools alone. Even so, it is worth pausing for a moment and putting this labour investment in wider comparative context. For example, Shelach et al. (2011) suggest that, in the same broad region seemingly more elaborate stone fortifications could later be made by Lower Xiajiadian (4000-3200 BP) villages such as Sanzuodian (三座店, perhaps with a population of several hundred people) without the need for wider pooling of human labour. However, Lower Xiajiadian sites were more densely scattered, probably longer-lasting and more aggregated than their Hongshan predecessors (e.g. Shao 1995), meaning that individual communities, or very limited cooperation amongst neighbouring ones, could bring together larger workforces. Moreover, apart from the possible exception of Dongshanzui (see discussion and note above), investment in Hongshan ceremonial sites occurred some distance away from settled areas and hence necessitated special purpose projects rather than everyday local additions. Suggestions that the burial customs at Niuheliang reflect influences from 
a range of neighbouring communities also argue in favour of this pooling of contributions (Yan 2006).

Turning to the effort and connections implied by portable material culture, most of the elaborate jade artefacts from the Niuheliang tombs were made from river pebbles of Xiuyan (岫岩) jade which could only be found in the east of Liaoning and beyond the Hongshan region (Wang et al. 2007; Wen 1990). Likewise, although plenty of painted pottery cylinders have been found in the Niuheliang area, no ceramic workshops or kilns have been identified and it seems likely that these important objects were also manufactured elsewhere and then transported to Niuheliang. The most important access routes to the Niuheliang area are a series of inter-linked river valleys. The Daling River flows from west to east across the mountains with many branch streams following a northeast to southwest direction that made them convenient both for the land and river transportation. In fact, the Niuheliang landscape encompasses one of these branches of Daling River (named the Ox River) that, even today, is on the route of the modern railway from Beijing to Shenyang and a major national road (G101). Local geological variability seems to have been important, with a particular kind of white limestone being the typical building material for coffins and altar bases, and several plausible local source outcrops exist in the Niuheliang area (with a long, later history of having been quarried). The large limestone slabs used in the Niuheliang monuments are typically about $40 \mathrm{~cm}$ in length and of a size that one person could carry (LPICRA 1986:7). Gneiss however is the most common bedrock in the immediate vicinity of Niuheliang (Mo et al. 2002: 179) —as we shall see below, most of the Niuheliang sites are found on this kind of geological unit cut into the metre or so of soft soil formed above them and, in the case of the larger tombs, even cut down into the bedrock itself.

\subsection{The Visual Landscape}

The visual affordances offered by certain landscapes have long been emphasised in archaeological studies of sacred places, particularly with regard to the way such visual properties might be further invested with social and cultural meanings (e.g. Fraser 1988; Tilley 1994; Zubrow 1994). Two inter-related features of the visual landscape at Niuheliang that we consider further below are: a) views of natural scenes and b) views among the artificial monuments. To the modern viewer, the most prominent general features in Niuheliang area are the sharp line of mountains rising up to the southeast. Much later on in Chinese history, high mountains were traditionally and consistently regarded as sacred places where heaven and earth met and where various forms of shamanic and/or other ritual practice might occur (Barnes 1999:117-119). ${ }^{5}$ This connection between heaven-and-earth cosmologies, animal forms and the exercise of religious power (e.g. captured by the later notion of

5 For example, later Chinese emperors typically held ceremonies on the top of famous mountains to legitimate their rule, particularly at the moment of succession. 
Wuism) is something that several authors have made very strongly with respect to Niuheliang (Rong 1993; Gu 2006; Cao 2007; Fu 1990; 2000), on the basis of finds such as jade artefacts thought to be in the form of specific animals, of a magical or religious human figure and of clouds (Figure 8a-b), as well as the undeniable importance ascribed to depositing circular ceremonial ceramics on the tops of hills. In our view, while shamanic practice may well have been important as a source of local secular and ritual authority, and the possibility of conceptual continuity with much later Chinese ritual or cosmology is certainly worth floating as an idea, both remain extremely difficult to confirm on the basis of the existing evidence. Regardless, the central role of nature worship and of investment in certain symbolically-charged images are the two factors of Niuheliang portable and fixed material culture that it is impossible to ignore, and this prompts us to explore visual affordances further in the modelling that follows below .

Likewise, far more specific visual meanings have been regularly ascribed to the mountain skyline of the Niuheliang complex since its archaeological discovery. In particular, great importance has hitherto been placed on a more isolated and distinctively-shaped mountain to the south-west of Niuheliang which, geologicallyspeaking, is part of what is, in local terms, a unique unit of porphyritic bedrock. The local name for this feature is Mulan Shan (木栏山), “Wood Column Mountain”, but regional archaeologists have suggested alternative names such as "Boar", "Pig-Head" or more recently "Bear" Mountain (Barnes with Guo 1996), based on a) the resemblance of the mountain to the top of an animal head (as seen from the front), b) an awareness of the long tradition of worshipping one or more of these animals in this region, and c) the prevalence of animal-shaped Honghan artefacts at Niuheliang (especially a famous carved jade loop in animal form that was found here: Figure 9a-b; CBCC and LPICRA: figure 95). These modern archaeological names are therefore meant to suggest the kinds of meanings that Hongshan communities may also have ascribed to the feature, and to propose some clear interpretative links with later Chinese or north-west Asian cosmologies. Again, we think that it remains difficult to do more than speculate about these tight symbolic associations, but regardless, it seems quite likely that the combination of this particular mountain's unusual shape, unusual bedrock and prominent skyline vista may indeed have encouraged some quite specific concepts of place.

In any event, the built monuments at Niuheliang may also have worked amongst themselves to construct a local cultural landscape of particular places and special meanings. For example, the Niuheliang structures emphasise visual contrast and colour in that the larger tombs were mainly made from white limestone with red stone sacrificial altars nearby and red, thick, cylindrical pots placed above them in rows that made them stand out from the background soils and bedrock (Guo 2010b). Most of the large sites within the overall complex are also fairly evenly distributed along the so-called Niuheliang ridge, which stretches from northeast to southwest. The most prominent place on this ridge is at the northern end where the "Goddess Temple" is located and the huge platform behind the temple undoubtedly re- 
emphasizes the importance of this northern section for the entire surrounding landscape. We further consider patterns of inter-visibility amongst these sites via formal modelling below.

\subsection{Multivariate Spatial Analysis}

\subsubsection{A Locational Model}

We can also test some of the hypothetical locational properties mentioned above in a more formal way via multivariate spatial analysis. Two separate groups of data will be modelled: a) all ceremonial sites in Niuheliang, and b) a subset of larger sites from the proposed "upper deposits" phase, in order to consider any possible differences between them. These groups will be compared via multivariate logistic regression in which the presence data are sites and the absence data are a set of random points placed within the area of systematic, and in some sense "full coverage", exploration at Niuheliang.

The variables chosen as independent covariates below are clearly not an exhaustive set, but are intentionally those that test informal associations either made by the authors in the field or already published in the interpretative literature. Table 1 summarises these variables, the data sources they are constructed from and any statistical pre-treatment they have received. Each variable were first explored for its distributional properties, its interactions with other possible covariates and for its significance as a univariate predictor. Thereafter, promising covariates were transformed if necessary and included in the multivariate model (with a final model being selected via stepwise minimisation of an Akaike Information Criterion, AIC). The digital elevation model (DEM) used here was interpolated on a $20 \mathrm{~m}$ grid from a 10 meter contours: all covariates were rasterised to the same resolution. One kind of variable worth slightly more extended consideration is that of visibility. Modern GIS software provides a range of tools for calculating and comparing the viewable area associated with a particular point in the landscape, known as its viewshed. The viewshed of the mountains that we use here is simply a binary map recording the areas from where at least one of the main mountain peaks to the southeast of Niuheliang could be seen in clear weather conditions. Likewise, a similar kind of viewshed was calculated and used further below to consider which sites are intervisible with the "Goddess Temple" or the pyramid-shaped building.

Significant variables are showed in the first row of Table 1 including low elevation, slope, more southeast-facing aspects, distance to the main river crossing, a fuzzy classification of ridge-like landforms, distance into/out of units of gneiss bedrock, and intervisibility with the mountainous area to the south. In particular, this last variable is treated carefully below: the exploration of sacred landscapes via GISbased viewshed analysis has attracted many archaeologists in recent years, as this technique has, rightly or wrongly, been touted as a GIS-led method that might be go beyond the consideration of straightforward environmental factors and to look at issues of human perception (see Zubrow 1994; Lake and Woodman 2003, Llobera 2003). In order to test if the view of mountains is truly significant for the choice of 
site location, two separate regression models have been compared: a) model A that begins with all significant univariate variables; b) model $B$ that excludes the mountain view variable.

Table 2 indicates the signed correlations between each variable chosen for model A. One point to note is that the mountain views variable is partly correlated with the aspect to the southeast $\left(r=0.551\right.$ or $\left.r^{2}=0.304\right)$, because the entire valley opens out to the southeast. Another variable, distance to the main river crossing is also slightly correlated with the mountain views ( $\mathrm{r}=-0.315$ or $\left.\mathrm{r}^{2}=0.099\right)$. These correlations urge a little caution in interpreting the results as evidence for explicit causal mechanisms, and we return to this issue below, but even so, the overall positive percentage of correct predictions (model A 88.4\%, model B 74.4\%), Akaike Information Criteria (model A 84.94, model B 87.94) and Receiver Operating Characteristic (ROC) curves (model A 0.884, model B 0.871) all suggest that model A is slightly more effective than model $B$ and hence that mountain views, whilst undeniably important in tandem with south-eastern aspects, may also be independently influential.

Model A and B addressed all sites in the Niuheliang complex. As a second stage of analysis, we also sought to consider only the larger built monuments, using the same approach. The reduced number of sites and non-sites in the sample still leads to predictor variables that are very significant, but with some continuing concerns over interdependence. Below we isolate patterns of intervisibility in other ways to confirm that it was indeed important for these larger sites, but we can also note in passing that compared to the smaller sites, the later-built larger ones were located in particularly homogenous places with a range of intersecting landscape affordances.

\subsubsection{Intervisibility Among Sites}

So far in terms of visibility, we have considered the rather simple case of the intervisibility of Niuheliang sites with the main mountainous area to the south. Given the above suggestion that this is a useful predictive factor, and more tentatively, that it might be an intentional feature of site location, we can also consider other aspects of the visual landscape. First of all, just how unusual is the overall amount of the landscape that you can see from the Niuheliang sites. Using a coarser $50 \mathrm{~m}$ DEM interpolated from $20 \mathrm{~m}$ contours with an appropriate buffer zone to control for edge effects (see Lake et al. 1998), viewer and target heights set to $1.5 \mathrm{~m}$, and a background $10 \%$ sample of random sites, we can calculate viewsheds that confirm, as the above regression models suggest, that these south-east facing sites do indeed have better overall visibility of the landscape (Figure 10). Furthermore, the vistas available from the larger sites are also larger than those from the smaller ones $(\mathrm{p}<0.05$; Figure 11$)$. We therefore suggest that it was partly the increased visual opportunities at certain already-active ceremonial locations at Niuheliang that prompted their more substantial investment with altars and elaborate burials. 
Taking this a step further, we can tentatively explore the visual network between the larger sites in a bit more detail. For example, intervisibility among these larger sites is also seemingly of some importance: site no.1 is where the "Goddess Temple" is located, associated with large altars surrounded by stone enclosure wall, while the so-called pyramid building, probably a huge altar, is site no.13. These two are distinctive not only for their exceptional finds but also on their special locations on hilltops where they are very often within visual range of the other sites. More formally, we can construct a visual network, this time using a finer-scale 20m DEM interpolated from $10 \mathrm{~m}$ contours, recording intervisibility between each of the 16 large sites (with viewpoint height set to $1.5 \mathrm{~m}$ and target to ground level). To explore the degree to which the results might be sensitive to inaccuracies in the DEM, we also re-run the analysis 100 times, in each case randomly perturbing all cells in the DEM by $\pm 1 \mathrm{~m}$ before re-running the viewsheds. The resulting visibility network shown in Table 3 is therefore probabilistic, with a 1 indicating that that the target site can always be seen from the viewpoint site in all runs, and a 0 indicating that it never can, with a range of possible values in-between indicating uncertainty. Thereafter, we use a Monte Carlo simulation - random re-labelling of which two sites represent bigger monuments like the pyramid building and "Goddess Temple", while keeping the visual relationships fixed. The result suggest at least the possibility that a visual focus on sites no.1 and no.13 was important for which sites became larger ones in the later phases at Niuheliang ( $p \sim 0.11$, using the percentile method and 10,000 iterations, and summing the probabilities of seeing site no. 1 and 13 from each other site), but there are clearly some considerable uncertainties associated with only minor changes in intervening landscape heights (and by extension probably also viewpoint and target heights), and further analysis with a much higher resolution elevation model and a palaeo-environmental reconstruction would be desirable.

\section{Other Hongshan Ceremonial Sites}

\subsection{Sijiazi}

The Hongshan ceremonial sites at Sijiazi are located 60 kilometres to the northeast of Niuheliang in southeastern Inner Mongolia. The character of the Sijiazi landscape is similar to that at Niuheliang: the mountains lie across this region from northeast to southwest with some prominent peaks to the southeast including the summit of Mt. Nuluerhu (known locally as Daqingshan/Duanqinshan, or Large Green Mountain in Chinese). Like Niuheliang, it is also on a perennial branch of the Daling River (the Laohushan River or Tiger Hill River in Chinese) that cuts through the mountains and is the main access route through the region. A systematic field survey of ca.70 $\mathrm{km}^{2}$ along the river valley has identified 8 ceremonial sites with tombs or altars and another 10 places where only pottery cylinder sherds were collected (IMAT and $M A B$ 2005). The most common local bedrock is either red volcanic tuff or yellow sandstone, which provide appropriate stone for altar bases. More generally, this 
sacred area in the upper Laohushan valley again suggests the existence of exclusive Hongshan sacred places that were physically separated from everyday settlement and secular life (Figure 12).

The largest site at Sijiazi is called Caomaoshan (Straw Hat Hill in Chinese) and excavations there have uncovered an elaborate altar and tombs (Shao 2004). The tombs were built with stone coffins and the skeletons were placed with their heads to the east, and with jade objects as the main offerings. These tombs show features that are broadly similar to those found in the upper deposits period at Niuheliang and therefore can tentatively be regarded as contemporary. The altar at Caomaoshan was built in as a three-layered distinctively-shaped stone construction surrounded by an enclosure wall. Some commentators have suggested its shape deliberately evokes that of a tortoise (Shao 2004), which in later Chinese cosmology symbolised the earth and appears to be one of the most popular themes among Hongshan jade objects. Some female figurines made from red tuff were also found at this site, which may indicate that it served a similar function to the "Goddess Temple" at Niuheliang.

The small sample at Sijiazi precludes any formal spatial analysis, but similar patterns to those at Niuheliang are arguably present here also. For example, there may well be a similar distinction between large and small sites within the overall Sijiazi complex and the eight known sites can arguably grouped into 4 distinct groups, each with an altar and associated tombs. The largest and most complex site at Caomaoshan is located on one of the most prominent hilltops on the northern side with wide surrounding views.

\subsection{Dongshanzui}

The ceremonial complex of Dongshanzui is located in the upper Daling River valley, just $30 \mathrm{~km}$ east of Niuheliang. It was the first such ceremonial landscape to be discovered and its excavation in the late 1970s had a great impact on Hongshan archaeological research (Guan and Zhang 1984). Recently, a systematic survey of a $200 \mathrm{~km}^{2}$ area around Dongshanzui has documented a landscape that includes at least four sub-groupings of ceremonial activity (Peterson et al. 2010; LPICRA et al. 2010). As a landscape, the area around Dongshanzui is similar to Niuheliang, with mountains stretching from northeast to southwest and the Daling River flowing through. The most view-prominent mountain peaks here are also in the southeast especially one locally called Majiazishan (Horse Framed Mountain in Chinese), which lies on the opposite side of a wide river flood plain. As at Niuheliang, all sites at Dongshanzui were found on the gneiss bedrock units. The main monument found at Dongshanzui is a huge stone construction of complex design, which takes up almost the whole surface area of the site. It seems to represent a complex of altars in both square or round shapes that are symmetrically arranged along a north-south axis line, surrounded by a stone enclosure wall and pottery cylinders. The sample is too small to be sure at this stage, but there might also be similar sub-distinctions among the ceremonial sites at Dongshanzui to the ones noted at Niuheliang, as only 
cylinder sherds and no monumental evidence have been found in some other localities. According to radiocarbon data, the stone altars in Dongshanzui site are contemporary with the larger sites at Niuheliang (Guo and Zhang 1984:10) with a recalibrated date centres on ca.5700 B.P. (Figure 7) and the site has also produced a lot of exotic artefacts comparable to those at Niuheliang, including animal-shaped jades, pottery vessels and pregnant female figurines.

Despite these similarities, a crucial difference between Dongshanzui and Niuheliang is that, at the former, these ceremonial activities are found in an area with settlement remains (although it remains unclear if this is contemporary or earlier), and at present, in the complete absence of tomb activity (Figure 13). Although further research in the region may conceivably alter or nuance this picture, at present it suggests that the ceremonial activities associated with the animal-shaped jade objects, pottery cylinders, female figurines and stone-clad altars were ones that were not exclusively be associated with burial practice alone, but under certain conditions could be deployed either for elite funerary or non-funerary rituals. Indeed, some tombs with painted pottery cylinders were also discovered at residential sites such as Fushan, while some stones circles were found on hilltops close to residential sites in the Chifeng survey area (Peterson et al. 2010: 5757; CICARP 2003:31,113). Therefore while a mixed set funerary and ceremonial activities at Niuheliang continues to stand out, we cannot assume it represents a ceremonial type site.

\section{Discussion}

The above discussion of Hongshan settlement and ceremonial landscapes has sought to offer context and wider insight into the dynamics of Hongshan society in general, particularly in its later phases. Ceremonial activities, and in some cases elite burial, focused on a few key sites, were clearly of great importance to large-scale integration of Hongshan society, especially given the evidence for very little hierarchical organisation in the settlement landscape itself. Although such sacred places are found in several different areas, they share many similarities in terms of their surrounding material and visual landscape. Most Hongshan ceremonial complexes found so far were preferentially located on the south-western margins of the overall Hongshan cultural area (as we perceive it archaeologically), on the tops of low hills, within river valleys, and with high mountains as background which led to them having expansive views of the surrounding countryside and potentially high levels of connection between individual locations. Manipulation of different kinds of local and/or exotic stone resource, for building and crafting, were clearly important, and we suspect their on-site manipulation in terms of type and colour, enabled micro-cosmographical expressions of perceived variability in the wider Hongshan landscape. Animal imagery is an important aspect of the portable material culture at these sites, with plausible but tentative identifications amongst the jade objects and figurines including owls, tortoises, dragons, bears, pigs, boars, hawks, fish, and silkworms (see also Guo 2009). It is also not inconceivable that certain built 
structures such as the altar complex at Caomaoshan or landforms such as Mt Mulan Shan at Niuheliang may have been ascribed specific similar animal forms and meanings, but it remains difficult to prove this archaeologically.

Shamanic rituals and chiefly authority are the two kinds of influence most heavily emphasised by other commentators with respect to Hongshan ceremonial activity (e.g. Barnes and Guo 1996; Peterson et al. 2010). We would also add that there seems to be a spiralling dynamic of investment at least some of these sites that involves: a) their appearance, on present evidence, only in the later part of the Hongshan period at perhaps ca.5700 B.P., and b) the signs of spatial and chronological stratification within this ceremonial landscapes, with the greatest levels of monumental and artefactual elaboration occurring in the suggested second phase of construction at Niuheliang. The quantitative analysis offered above also suggests that one feature of this latest stage, at Niuheliang at least, was the more concrete formalisation of the material relationships and landscape meanings associated with elite ritual activity, In particular, spatially and contextually structured combinations of different materials - for example clay and stone to name the two most archaeologically obvious - for both fixed installations and portable material culture, and of both local and exotic provenance. In terms of location, the larger, later sites at Niuheliang also laid more emphasis on a structured internal arrangement, possibly on intervisibility among localities and a position along a central axis of activity, with two prominent monuments, the "Goddess Temple" and pyramid-shaped building at either end. It is also possible to argue that the substantially greater investment so far documented at Niuheliang itself, by comparison to other known ceremonial sites suggests it was playing an increasingly important regional role. In any case, a plausible wider explanation for these increasingly formal landscape relationships is that they reflected and consolidated wider patterns of social and political stratification at this time, particularly in the Hongshan south-west.

The contrast with Hongshan settlement patterns is striking. Although both settlement and ceremonial sites can be seen to group into looser aggregations at several scales, and occasionally larger villages are found, there remain few if any signs of an organised settlement hierarchy. Moreover, some work on residential sites suggests both limited deposit build-up at any one locality and exploitation of a variety of landscapes (Teng 2010), at least raising the possibility that Hongshan residences shifted from time to time (though such a conclusion must remain tentative and we cannot as yet speculate about the possible tempo of any shifts if they did happen). In any case, under such circumstances of limited settlement hierarchy and possible non-stable residence, we can argue that, by the later phases of the Hongshan period at least certain ceremonial sites were becoming the key integrative components that promoted the social, religious and political credentials of a regional elite. 


\section{Acknowledgements}

This research has been fund both by ICCHA (International Center for Chinese Heritage and Archaeology) and the project of "Formation and Early Development of Chinese Civilization from 3500 to 1500BC: Research on Social Structure Reflected by Settlement Patterns". We are also grateful to Dr. Xinwei Li for providing with survey data from Sijiazi and the three anonymous reviewers for their careful readings and valuable advice. 


\section{References}

Barnes, G. L. and Guo, D., 1996. The Ritual Landscape of 'Boar Mountain' Basin: The Niuheliang Site Complex of North-Eastern China, World Archaeology 28: 209-219.

Barnes, G. L., 1999. Buddhist Landscape of East Asia. In: Ashmore, A., and Knapp, A.B. (eds.), Archaeologies of Landscape. Blackwell, Oxford, pp.101-123.

Barrett, J., 1999. The mythical landscapes of the British Iron Age. In: Ashmore, A., and Knapp, A.B. (eds.), Archaeologies of Landscape. Blackwell, Oxford, pp.253-265.

Bradley, R., 1998. Ruined buildings, ruined stones, enclosures, tombs and natural places in the Neolithic of south-west England. World Archaeology 30: 13-22.

Bradley, R., 2000. An Archaeology of Natural Places. Routledge, London.

Cao, Y., 2007. Hongshan wenhua yuqi yu samanjiao (The Hongshan jade and the Shammanism). Journal of Chifeng University (Soc Sci) 28 (5): 9-10. (in Chinese)

Cultural Bureau of Chaoyang City (CBCC) and Liaoning Provincial Institute of Cultural Relics and Archaeology (LPICRA) 2004. Niuheliang Site. Academy Press, Beijing.

Fang, D., and Liu B., 1984. Fuxinxian hutougou hongshan wenhua yuqi mu (The Hongshan tombs with jade in Hutougou, Fuxin County). Wenwu 6: 1-5. (in Chinese)

Fraser, D., 1988. The orientation of visibility from the Chambered Tombs of Eday, Orkney. In: Ruggles, C. L. N. (Ed.), Records in Stone. Cambridge University Press, Cambridge, pp. 325-337.

Fu, Y., 1990. Samanjiao yu shenhua (The Shammanism and the mythology). Liaoning University Press, Shenyang. (in Chinese)

Fu, Y., 2000. Saman lun (The Shammanism). Liaoning Renmin Press, Shenyang. (in Chinese)

Gibson, J.J. 1986. The Ecological Approach to Visual Perception. Erlbaum, London.

Gu, F., 2006 Samanjiao tedian dui Hongshan wenhua yuqi yanjiu de yixie qishi (Some inspirations from the Shammanism to the studies of Hongshan jade). In: Xi, Y. and Liu, G. (eds.), Hongshan wenhua yanjiu: 2004 nian hongshan wenhua guojie xueshu yantaohui lunwenji (Studies on the Hongshan Culture: collections of the papers for 2004 international conference of the Hongshan Culture, Chifeng). Wenwu Press, Beijing, pp.359-378. (in Chinese)

Guo, D., 2005. Hongshan wenhua (Hongshan culture). Wenwu Press, Beijing. (in Chinese) 
Guo, D., 2010a. Niuheliang yizhi suojian dongbei nanbu zaoqi juluo yanbian yu wenming jincheng (Early settlement patterns and civilized process in the southern part of Northeast China from research at Niuheliang). In: Institute of Archaeology, Chinese Academy of Social Science and School of Archaeology and Cultural Relics, Zhengzhou (eds.), Zhongguo juluo kaogu de lilun yu shijian (The theories and methods of settlement archaeology in China). Science Press, Beijing, pp.273-286. (in Chinese)

Guo, D., 2010b. Qianyan (Preface). In: Guo, D. and Hong, D. (eds.), Hongshan wenhua yuqi jianshang (A Study of Hongshan Culture Jades). Cultural Relics Press, Beijing, pp.14-27. (in Chinese and English)

Guo, D., and Ma, S., 1985. Yi liaohe liuyu wei zhongxin de xinsh.iqi wenhua zhu wenti (Some problems associated with Neolithic cultures in the areas around the Liao River valley). Kaogu Xuebao 4:417-443. (in Chinese)

Guo, D., and Zhang, K., 1984. Liaoningsheng kazuoxian dongshanzui hongshan wenhua jianzhuqunzhi fajue jianbao (Preliminary report on the excavation of architectural groups in Dongshanzui, Kazuo County, Liaoning Province). Wenwu 11: 1-11. (in Chinese)

Hua, Y., 1994. Niuheliang niushenmiao pingtai dongpo tongxingqiqun yicun fajue jianbao (Preliminary report on the excavation of pottery cylinder remains on the eastern slope of the platform near the Goddess Temple at Niuheliang). Wenwu 5: 5459,82. (in Chinese)

Hua, Y., and Yang, R., 1998. Hongshan wenhua muzang pouxi (Analysis on Hongshan tombs). In: Department of Archaeology, Jilin University (ed.), Qingguoji (Collection of Green Fruits: Collected Works for the Tenth Anniversary of the Archaeology Department of Jilin University). Knowledge Publishing House, Beijing, pp.35-43. (in Chinese)

Inner Mongolia Archaeological Team, Institute of Archaeology, Chinese Academy of Social Science (IMAT), 1982. Chifeng xishuiquan hongshan wenhua yizhi. (Hongshan site of Xishuiquan, Chifeng). Kaogu Xuebao 2: 183-197. (in Chinese)

Inner Mongolia Provincial Institute of Cultural Relics and Archaeology (IMPICRA), 1994. Balinzuoqi youhaocun erdaoliang hongshan wenhua yizhi fajue jianbao. (Preliminary report on the excavation of Hongshan site in Erdaoliang, Youhao village, Balinzuo Banner). In: Li, Y. and Wei, J. (eds.), Neimenggu Wenwu Kaogu Wenji, Vol. 1. Zhongguo Dabaike Quanshu Press, Beijing, pp.96-113. (in Chinese)

Inner Mongolia Provincial Institute of Cultural Relics and Archaeology (IMPICRA), 2004. Baiyinchanghan: Xinshiqi shidai yizhi fajue baogao (Baiyinchanghan: Report on the excavation of Neolithic site). Science Press, Beijing. (in Chinese) 
Inner Mongolia Archaeological Team, Institute of Archaeology, Chinese Academy of Social Science (IMAT) and Museum of Aohan Banner, Inner Mongolia (MAB), 2005. Neimenggu aohanqi banghe laohushanhe liuyu xinshiqishidai yizhi diaocha jianbao (The preliminary report on the regional survey of Neolithic sites in the valleys of Bang River and Laohushan River in Aohan Banner, Inner Mongolia). Kaogu 3: 3-20. (in Chinese)

Institute of Archaeology, Chinese Academy of Social Sciences (IACASS) (eds.), 1991. Zhongguo kaoguxue zhong tanshisi niandai shujuji (The C-14 data collection of Chinese archaeology). Cultural Relics Press, Beijing. (in Chinese)

Lake, M., Woodman, P., and Mithen, S., 1998. Tailoring GIS software for archaeological applications: an example concerning viewshed analysis. Journal of Archaeological Science 25: 27-38.

Lake, M W and Woodman, P E, 2003. Visibility studies in archaeology: A review and case study. Environment and Planning B: Planning and Design 30:689-707.

Li, D., 1986. Liaoning lingyuanxian sanguandianzi chengzishan yizhi shijue baogao (Report on the preliminary excavation of the Chengzishan site in Sanguandianzi, Lingyuan County, Liaoning Province). Kaogu 6: 497-510. (in Chinese)

Liaoning Provincial Institute of Cultural Relics and Archaeology (LPICRA), 1986. Liaoning niuheliang hongshan wenhua nushenmiao yu jishizhong fajue jianbao (Preliminary report on the excavation of "Goddess Temple" and stone tombs in Niuheliang, Liaoning Province). Wenwu 8: 1-17. (in Chinese)

Liaoning Provincial Institute of Cultural Relics and Archaeology (LPICRA), 1997a. Liaoning niuheliang dier didian yihao zhong 21 hao mu fajue jianbao (Preliminary report on the excavation of stone tomb no. 21 of tomb group 1 in locale 2 of Niuheliang, Liaoning Province). Wenwu 8: 9-14. (in Chinese)

Liaoning Provincial Institute of Cultural Relics and Archaeology (LPICRA), 1997b. Liaoning niuheliang dier didian sihao zhong tongxingqi mu de fajue (Preliminary report on the excavation of pottery cylinder tomb no. 4 in locale 2 of Niuheliang, Liaoning Province). Wenwu 8: 15-19. (in Chinese)

Liaoning Provincial Institute of Cultural Relics and Archaeology (LPICRA), 1997c. Liaoning niuheliang diwu didian yihao zhong zhongxin damu M1 fajue jianbao (Preliminary report on the excavation of the central tomb M1 in stone tomb group 1 in locale 5 of Niuheliang, Liaoning Province). Wenwu 8: 4-8. (in Chinese)

Liaoning Provincial Institute of Cultural Relics and Archaeology (LPICRA), 2001. Liaoning lingyuanshi niuheliang yizhi diwu didian 1998-1999 niandu de fajue (The excavation of locale 5 in Niuheliang, Lingyuan city, Liaoning Province in 1998-1999). Kaogu 8: 9-14. (in Chinese) 
Liaoning Provincial Institute of Cultural Relics and Archaeology (LPICRA), 2008a. Niuheliang hongshan wenhua dier didian yihao zhong shiguan mu de fajue (Excavation of the Hongshan stone tombs no.1 in locale 2 of Niuheliang). Wenwu 10: 15-33. (in Chinese)

Liaoning Provincial Institute of Cultural Relics and Archaeology (LPICRA), 2008b. Niuheliang di shiliu didian hongshan wenhua jishizhong zhongxin damu fajue jianbao (Preliminary report on the excavation of Hongshan central tomb in locale 16 of Niuheliang). Wenwu 10: 4-14. (in Chinese)

Liaoning Provincial Institute of Cultural Relics and Archaeology (LPICRA), Department of Anthropology, University of Pittsburgh, and University of Hawai'I. 2010. Liaoning dalinghe shangyou liuyu kaogu diaocha jianbao (Preliminary report on the archaeological survey to the Upper Reach of Daling River, Liaoning Province). Kaogu 5: 24-35. (in Chinese)

Llobera, M. 2001. Building Past Landscape Perception With GIS: Understanding Topographic Prominence. Journal of Archaeological Science 28: 1005-1014.

Llobera, M. 2003 Extending GIS based analysis: the concept of visualscape. International Journal of Geographic Information Science 1(17):1-25.

Mo, D., Yang, X., Wang, H., Li, S., Guo, D., and Zhu, D., 2002. Hongshan wenhua niuheliang yizhi xingcheng de huanjing beijing yu rendi guanxi yanjiu (The study on the environmental background and man-land relationship of Niuheliang site, Hongshan culture). Quaternary Science 22 (2): 174-181. (in Chinese)

Nelson, S. M. 1998. Pigs in the Hongshan Culture. In: Nelson, S.M. (ed.), Ancestors for the Pigs: Pigs in Prehistory. University of Pennsylvania Museum of Archaeology and Anthropology, Philadelphia, pp.99-107.

Peterson, C.E., Lu, X., Drennan, R.D. and Zhu, D. 2010 Hongshan chiefly communities in Neolithic northeastern China. Papers of the National Academy of Sciences 107.13: 5756-5761.

Rong, G., 1993. Dongshanzui hongshan wenhua jisi yizhi yu woguo gudai beifang minzu de samanjiao xinyang (The ceremonial site of Dongshanzui and the Shammanism in ancient north China). Study of Ethnology 1: 38-40. (in Chinese)

Shao, G., 1995. Gaishu aohanqi de hongshan wenhua yizhi fenbu (General summary on the distribution of Hongshan sites in Aohan Banner). In: International Centre for the Chinese Northern Cultures, Chifeng (ed.), Zhongguo beifang gudai wenhua guoji xueshu yantaohui lunwenji (Collections of the International Conference for the Ancient Cultures in North China). Wenshi Press, Beijing, pp.97-102. (in Chinese) 
Shao, G., 2004. Caomaoshan jisi yizhiqun (The ceremonial sites in Caomaoshan). In: Shao, G. (ed.), Aohan wenwu jinghua (Cream of Antiquities from Aohan). Neimenggu Wenhua Press, Hailaer, pp.27-29. (in Chinese)

Shelach, G. 2006 Economic adaptation, community structure, and sharing strategies of households at early sedentary communities in northeast China. Journal of Anthropological Archaeology 25: 318-345.

Shelach, G., K. Raphael, and Y. Jaffe., 2011. Sanzuodian: The Structure, Function and Social Significance of the Earliest Stone Fortified Sites in China. Antiquity 85: 11-26

$\mathrm{Su}, \mathrm{B} ., 1997$. Zhonghua wenming qiyuan xintan (New investigations on the origin of Chinese Civilization). Shangwu Press, Hong Kong. (in Chinese)

Suo, X., and Li, S., 2007. Niuheliang yizhi hongshan wenhua yicun fenqi chutan (Preliminary study on the chronology of Hongshan remains in Niuheliang site). Kaogu 10: 52-61. (in Chinese)

Teng, M., 2010. GIS zai banzhijianhe zhongyou huanjing kaogu zhong de yingyong (The application of GIS in the environmental analysis in the middle of Banzhijianhe valley). Kaogu Yu Wenwu 1: 91-99. (in Chinese)

The Chifeng International Collaborative Archaeological Research Project (CICARP), 2003. Regional Archaeology in Eastern Inner Mongolia: A Methodological Exploration. Science Press, Beijing. (in Chinese and English)

Tilley, C., 1994. A Phenomenology of Landscape: Paths, Places and Monuments. Berg, Oxford.

Tilley, C., 1996. The powers of rocks: topography and monument construction on Bodmin Moor. World Archaeology 28: 161-176.

Wang, S., Zhao, C., Yu, G., Yun, X., and Duan, T., 2007. Zhongguo Xiuyan yu (Xiuyan jades in China). Science Press, Beijing. (in Chinese)

Wei, F., 1994. Niuheliang hongshan wenhua disan didian jishizhong shiguan mu (The excavation of the stone tombs in the locale 3 of Hongshan site in Niuheliang). Liaohai Wenwu Xuekan 1: 9-13,101. (in Chinese)

Wen, G., 1990. Zhongguo guyu de yanjiu (The research on the ancient jades in China). Jiancai Dizhi 2: 2-10. (in Chinese)

Yang, H., 1994. Liaoxi diqu xinshiqi tongshi bingyong shidai kaogu wenhua xulie yu fenqi (The seriation and chronology of archaeological cultures from Neolithic to Chalcolithic periods in west of Liaoning). Wenwu 5: 37-52. (in Chinese) 
Yan, W., 2006 Hongshan wenhua wushinian: zai hongshan wenhua guoji xueshu yantaohui shang de jianghua (The Fifty anniversary of Hongshan culture: speech in the international conference of Hongshan culture). In: Xi, Y. and Liu, G. (eds.), Hongshan wenhua yanjiu: 2004 nian hongshan wenhua guojie xueshu yantaohui lunwenji (Studies on the Hongshan Culture: collections of the papers for 2004 international conference of the Hongshan Culture, Chifeng). Wenwu Press, Beijing, pp.5-11. (in Chinese)

Zhang, X., 1991. Hongshan wenhua fenqi chutan (The preliminary research on the chronology of Hongshan culture). Kaogu 8: 727-736. (in Chinese)

Zhang, Z., and Zhu, Y., 1994. Yuangu shidai (The ancient period). In: Zhongguo tongshi (China General History). Shanghai People's Press, Shanghai, pp.358-388. (in Chinese)

Zhao, Z., 2005. Cong xinglonggou yizhi fuxuan jieguo tan zhongguo beifang hanzuo nongye qiyuan wenti (Research on the origin of millet cultivation in North China according to the floatation samples from Xinglonggou site). In: Department of Archaeology and Museum, Nanjing Normal University (ed.), Dongya Guwu (East Asian Antiquities). Science Press, Beijing, pp.188-199. (in Chinese)

Zubrow, E., 1994. Knowledge, representation and archaeology: a cognitive example using GIS. In: Renfrew, C., and Zubrow, E. (eds.), The ancient mind - elements of cognitive archaeology. Cambridge University Press, Cambridge, pp.107-118.

\section{Figure caption}

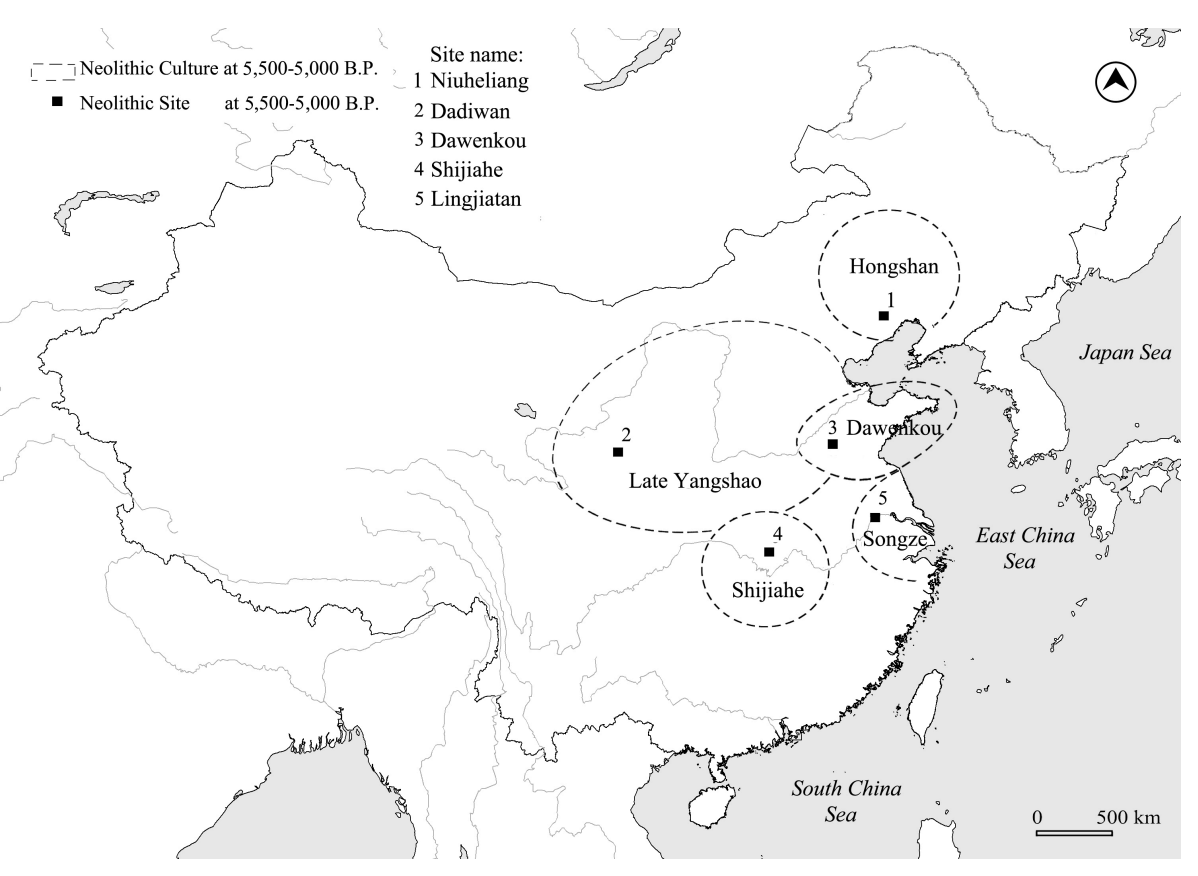


Figure 1: Map of the main Neolithic cultural groups documented in China at ca.5,500-5,000BP

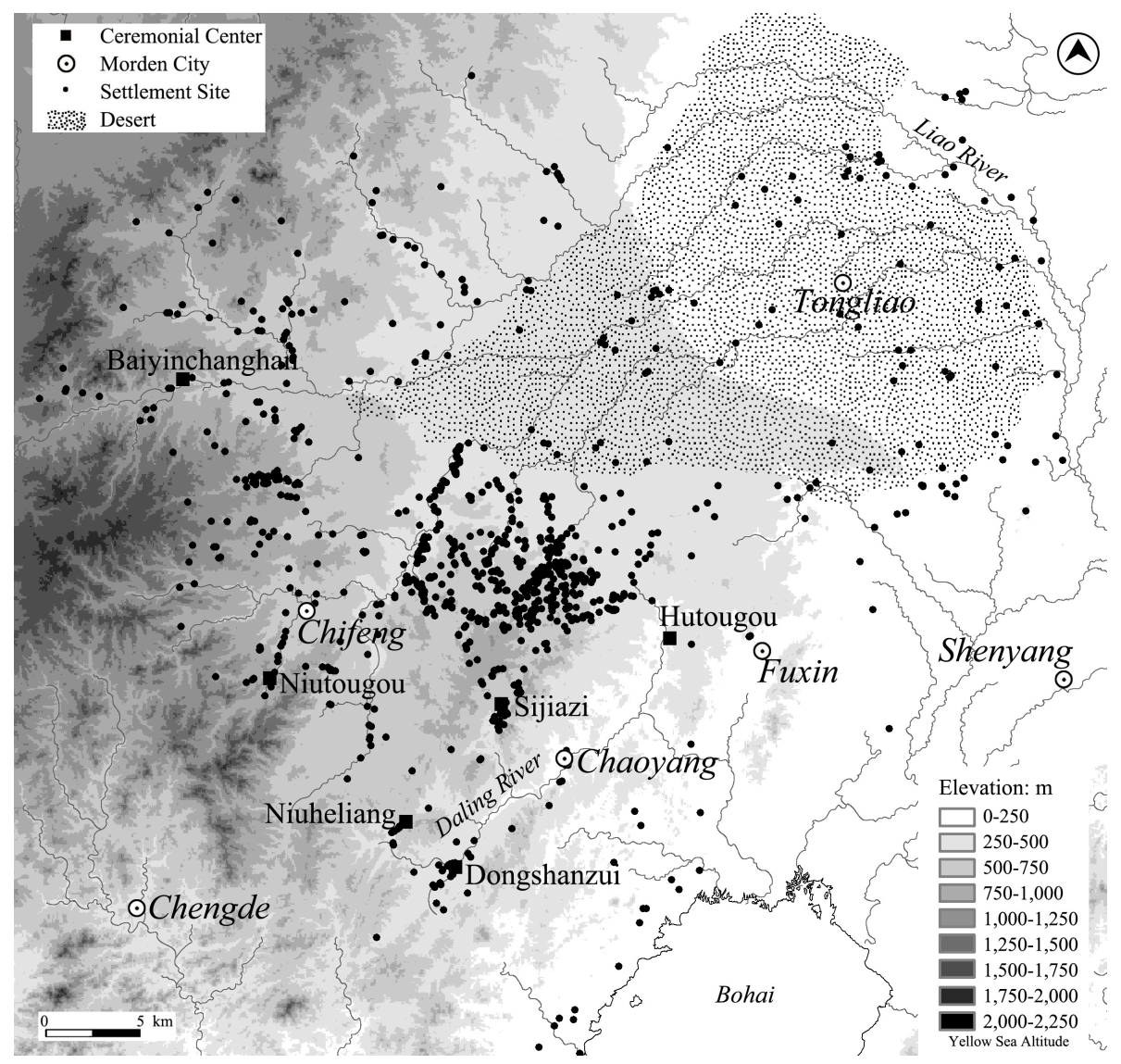

Figure 2: Map of the main Hongshan sites 


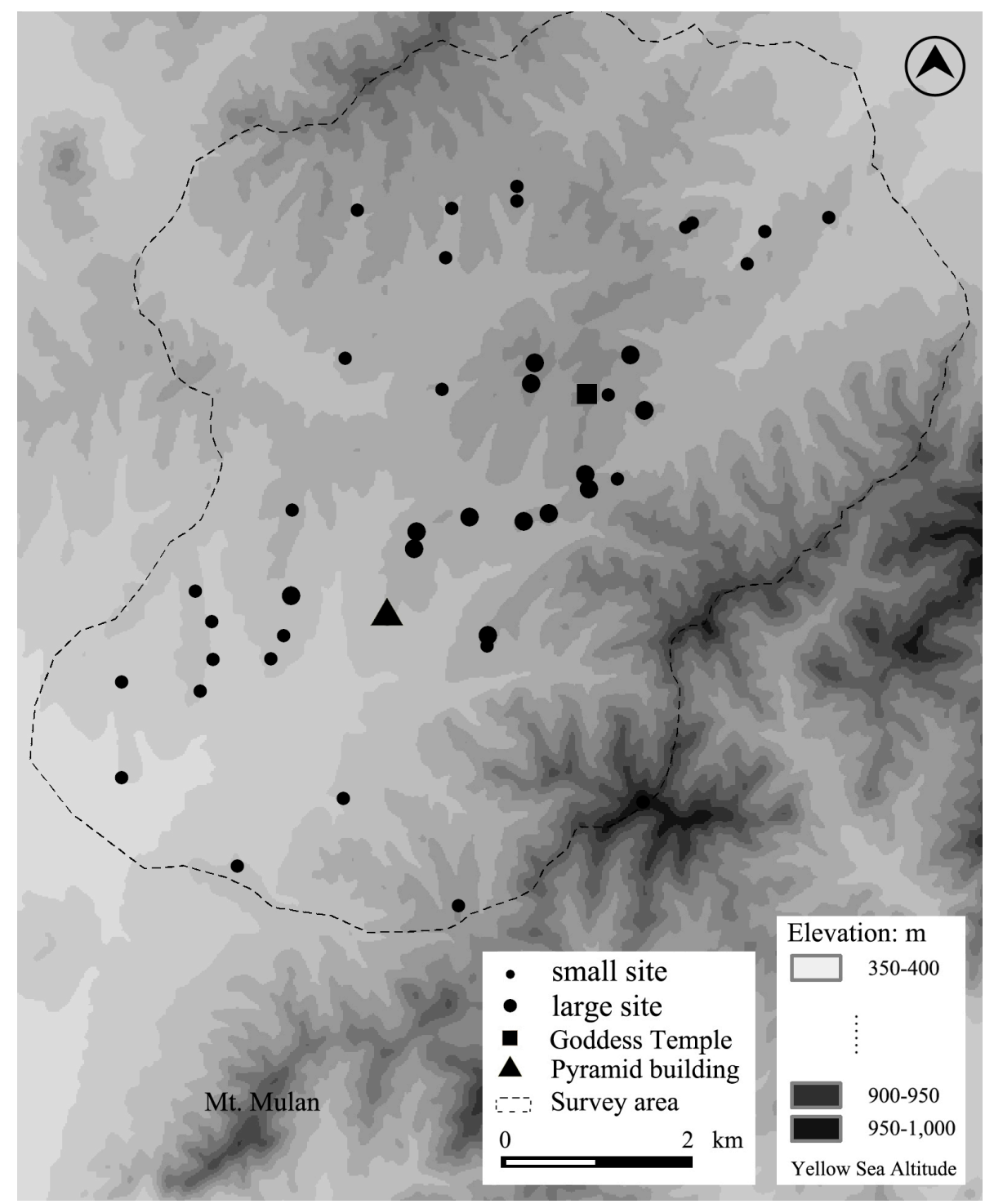

Figure 3: Distribution map of the ceremonial sites at Niuheliang 

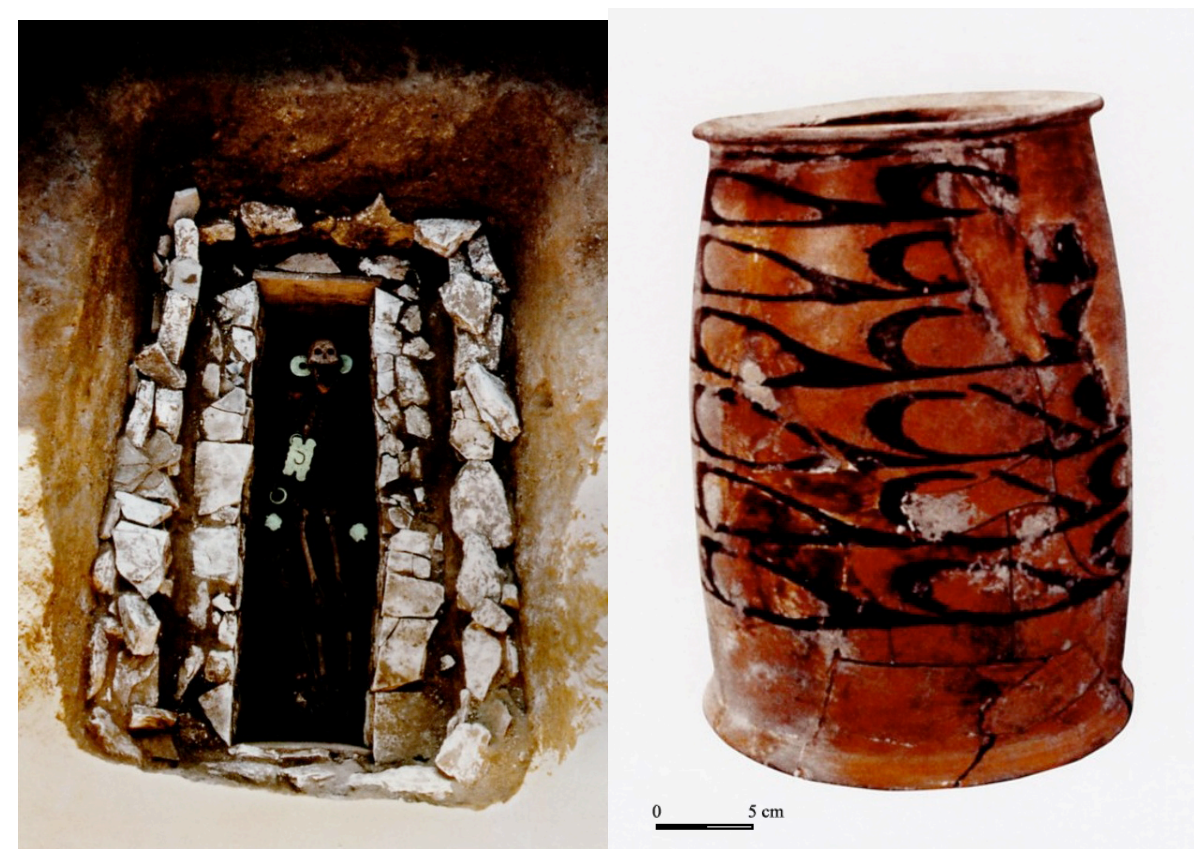

Figure 4: Hongshan remains at Niuheliang: a) a larger tomb, b) a pottery cylinder 


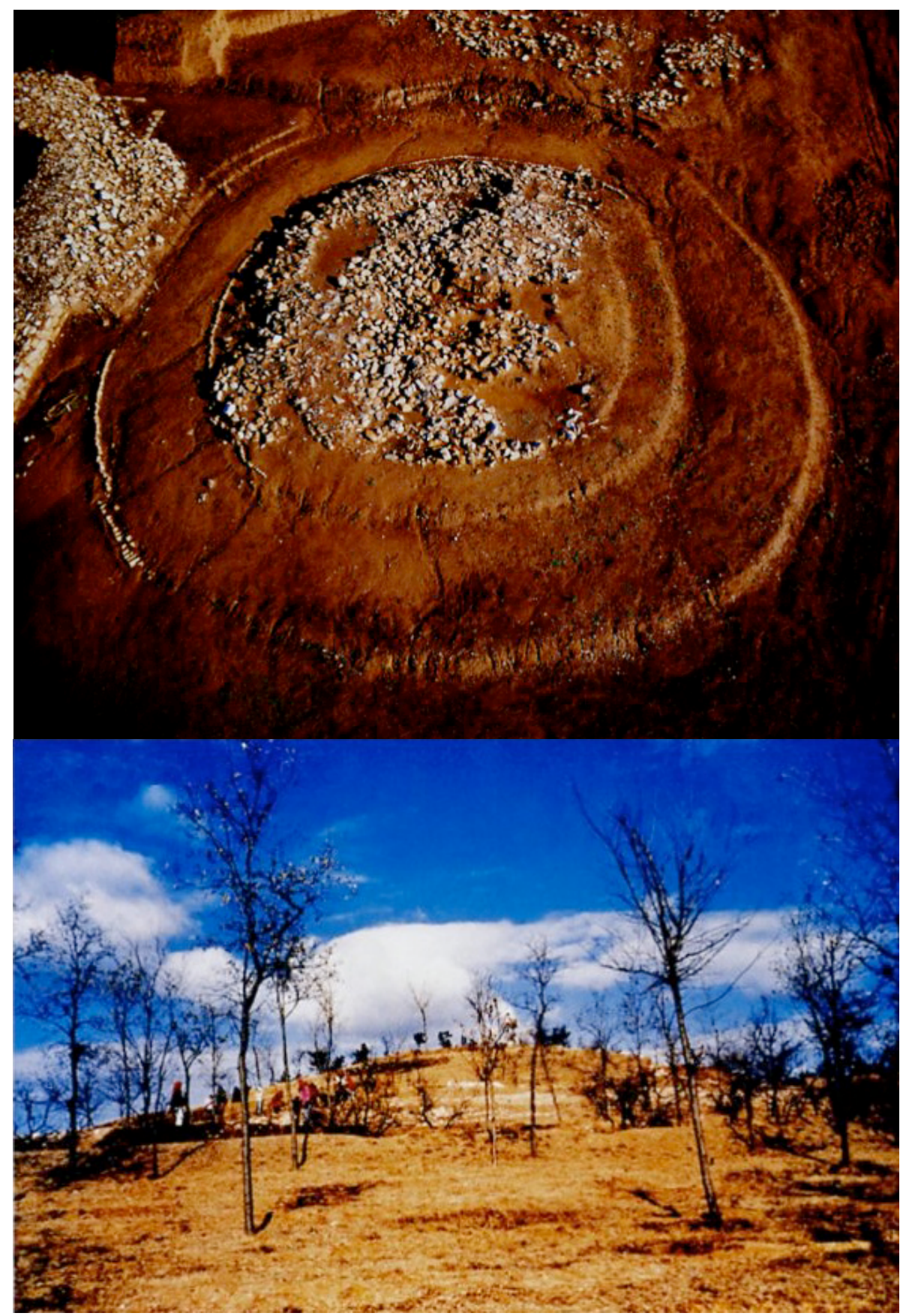

Figure 5: Hongshan altars at Niuheliang: a) Site No.2, b) Site No.13 


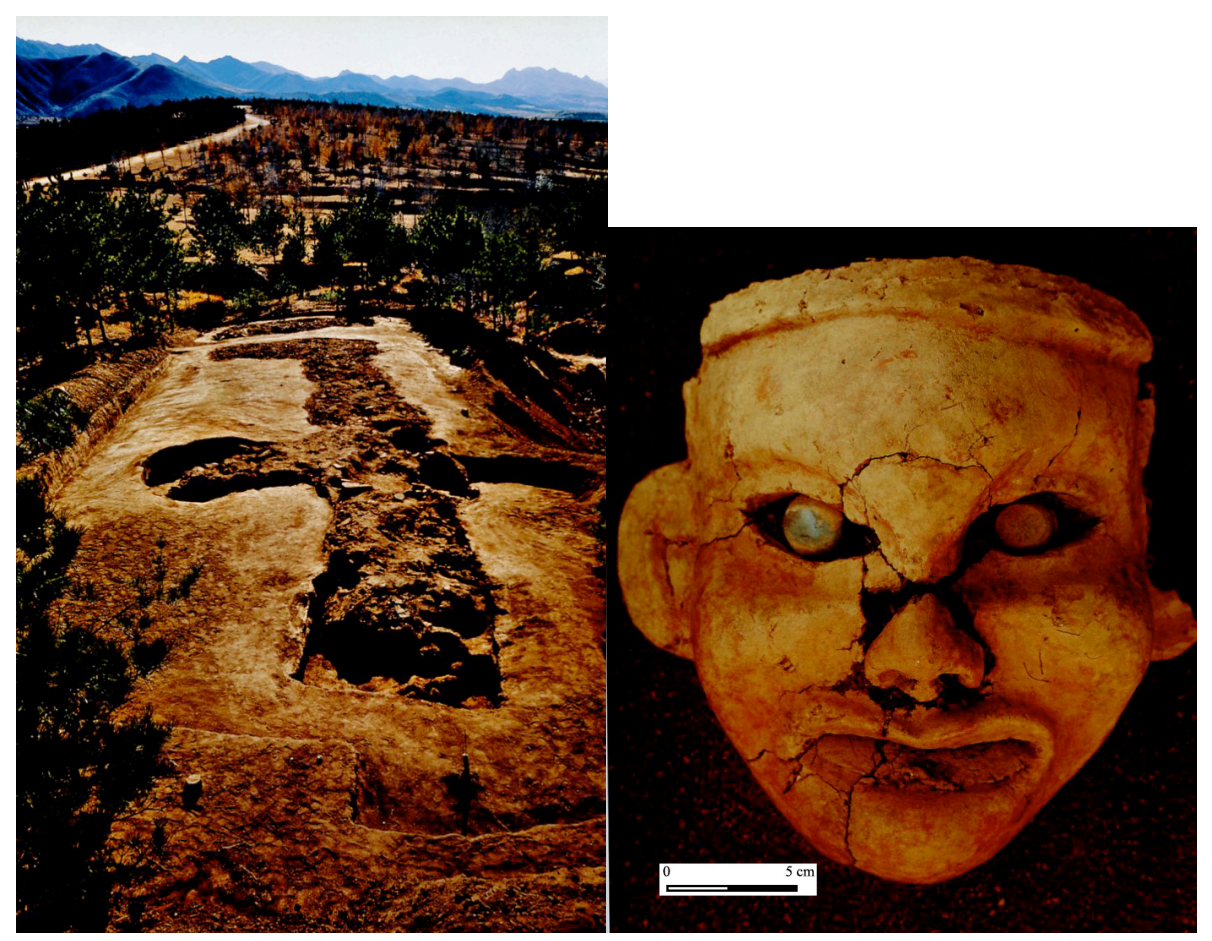

Figure 6: The "Goddess Temple" (site no. 1) at Niuheliang: a) Overview of the main structure, b) A clay female face found in the "Goddess Temple"

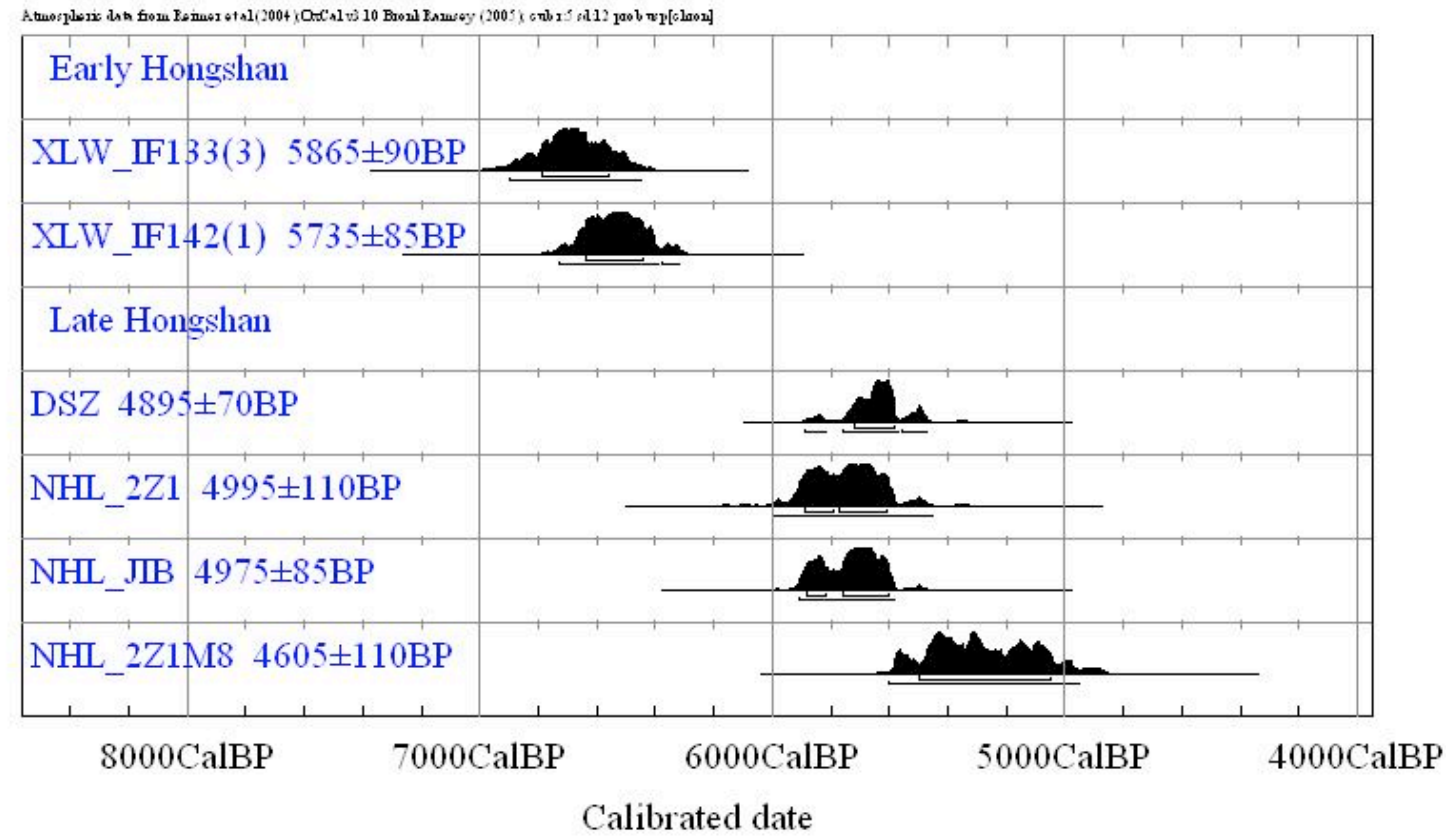

Figure 7: Calibrated radiocarbon dates from Hongshan sites 


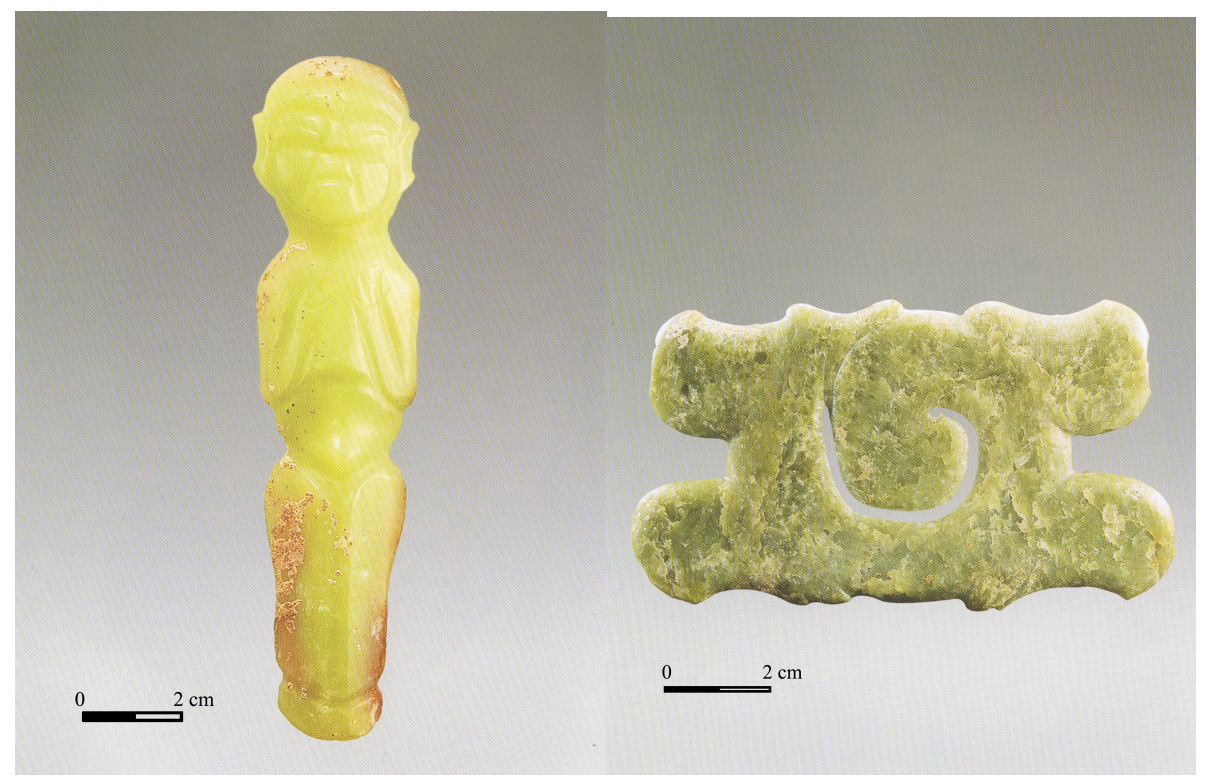

Figure 8: Jade objects from Niuheliang tombs

a: A human figure, sometimes thought to be a shaman

b: A possible cloud shape 

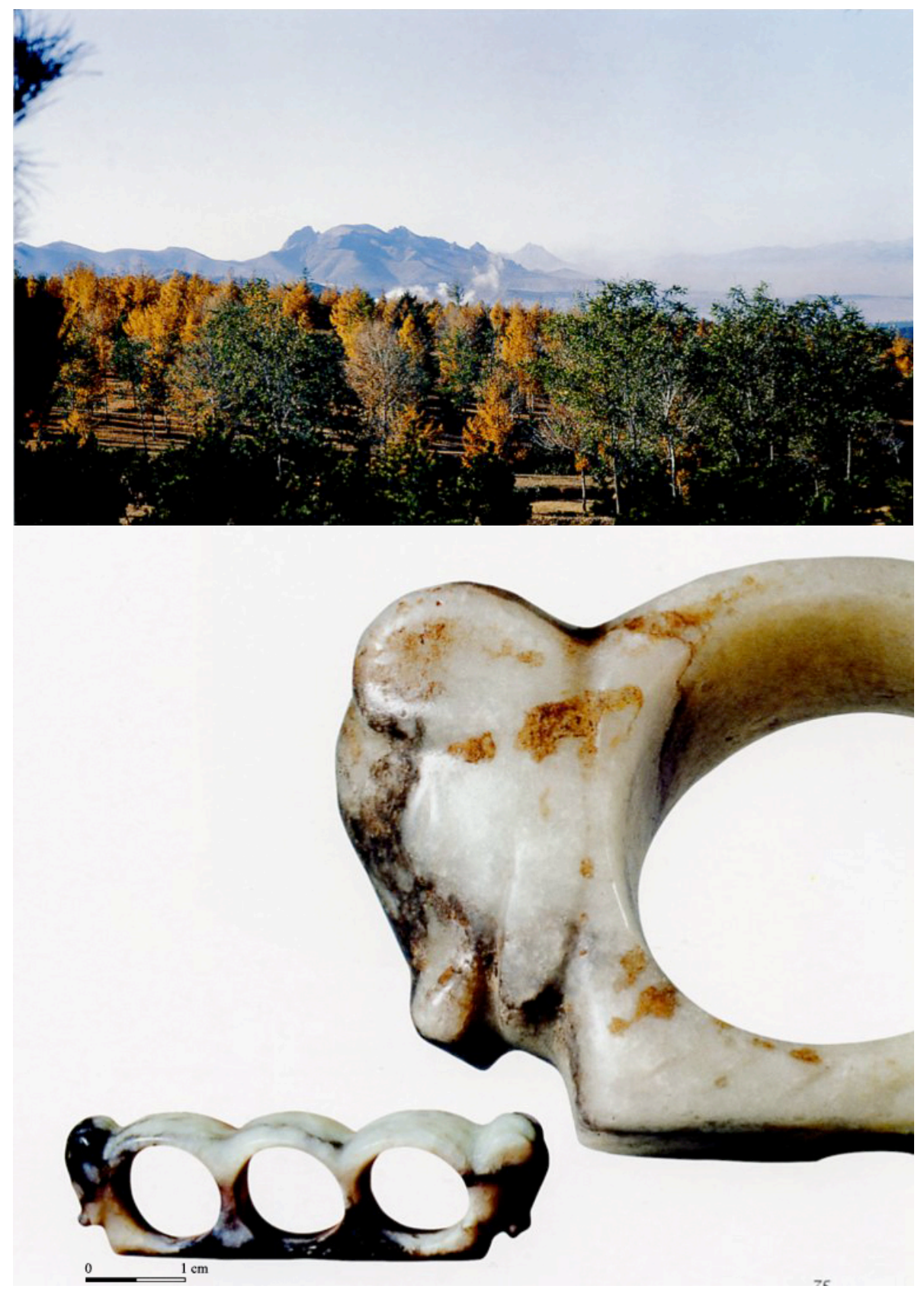

Figure 9: Animal imagery associated with Niuheliang: a) Mulan Shan, a mountain whose outline on the horizon has been likened by some to a boar, pig or bear, b) A jade object from a Niuheliang tomb, thought by some to be in the shape of boar or bear 

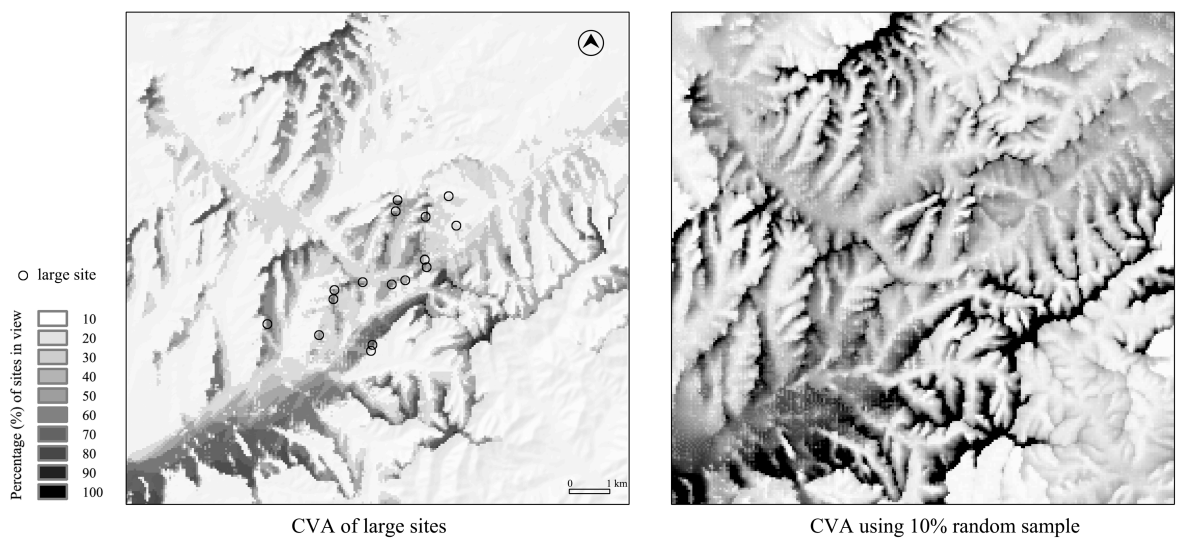

Figure 10: Cumulative viewshed analysis (CVA) of Niuheliang sites a: CVA from larger sites at Niuheliang

b: CVA based on $10 \%$ random sample cells

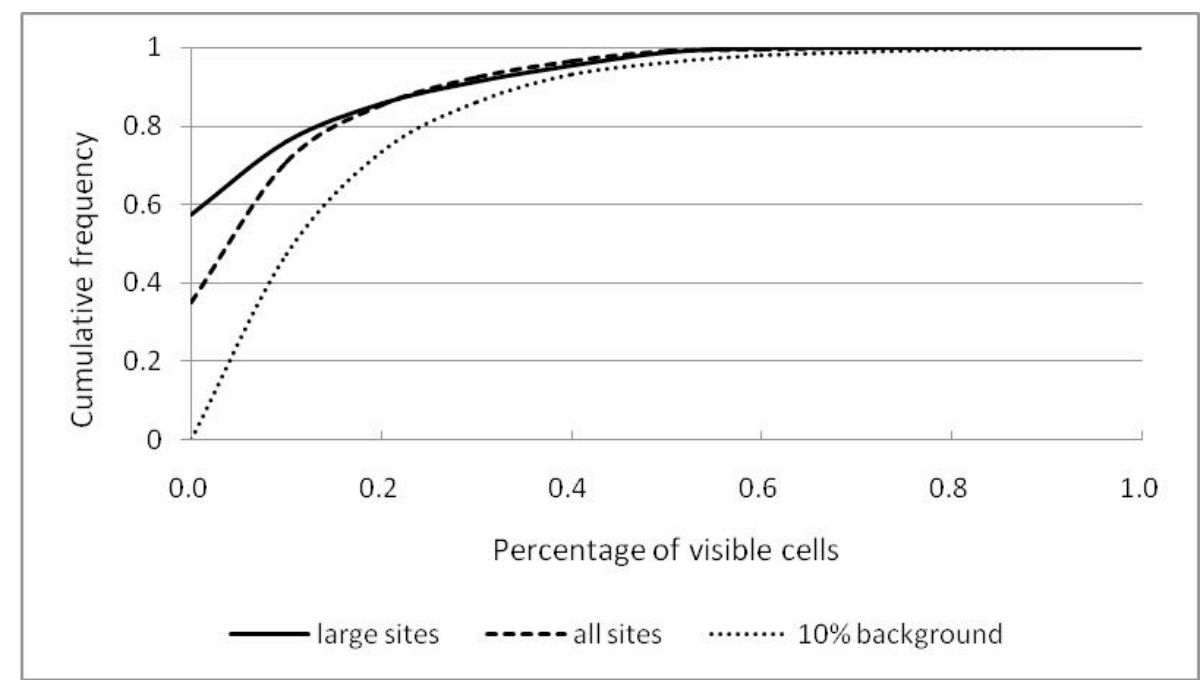

Figure 11: Cumulative percentage of visible sites in Niuheliang with $10 \%$ background sample 


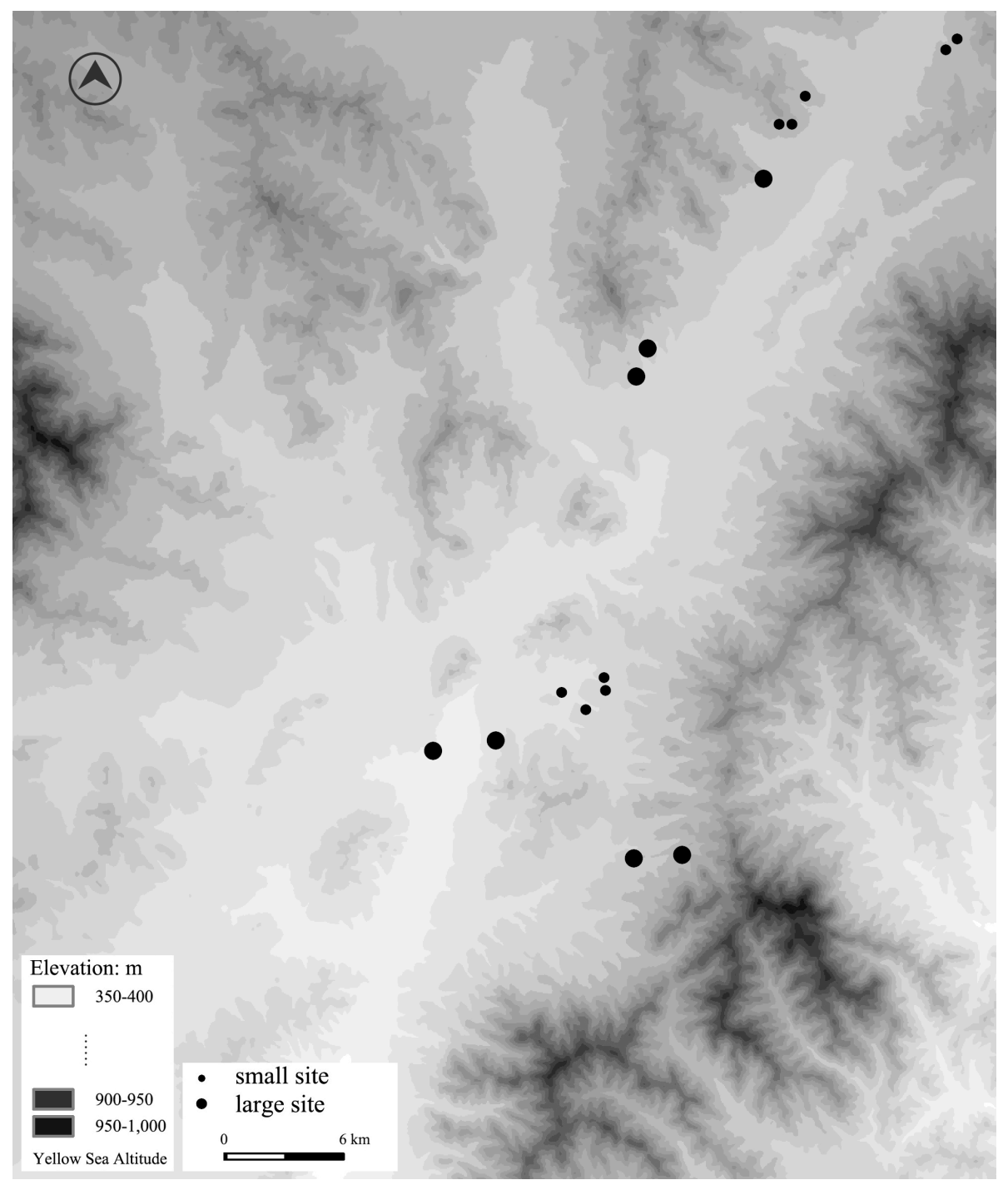

Figure 12: Distribution map of the ceremonial sites at Sijiazi 


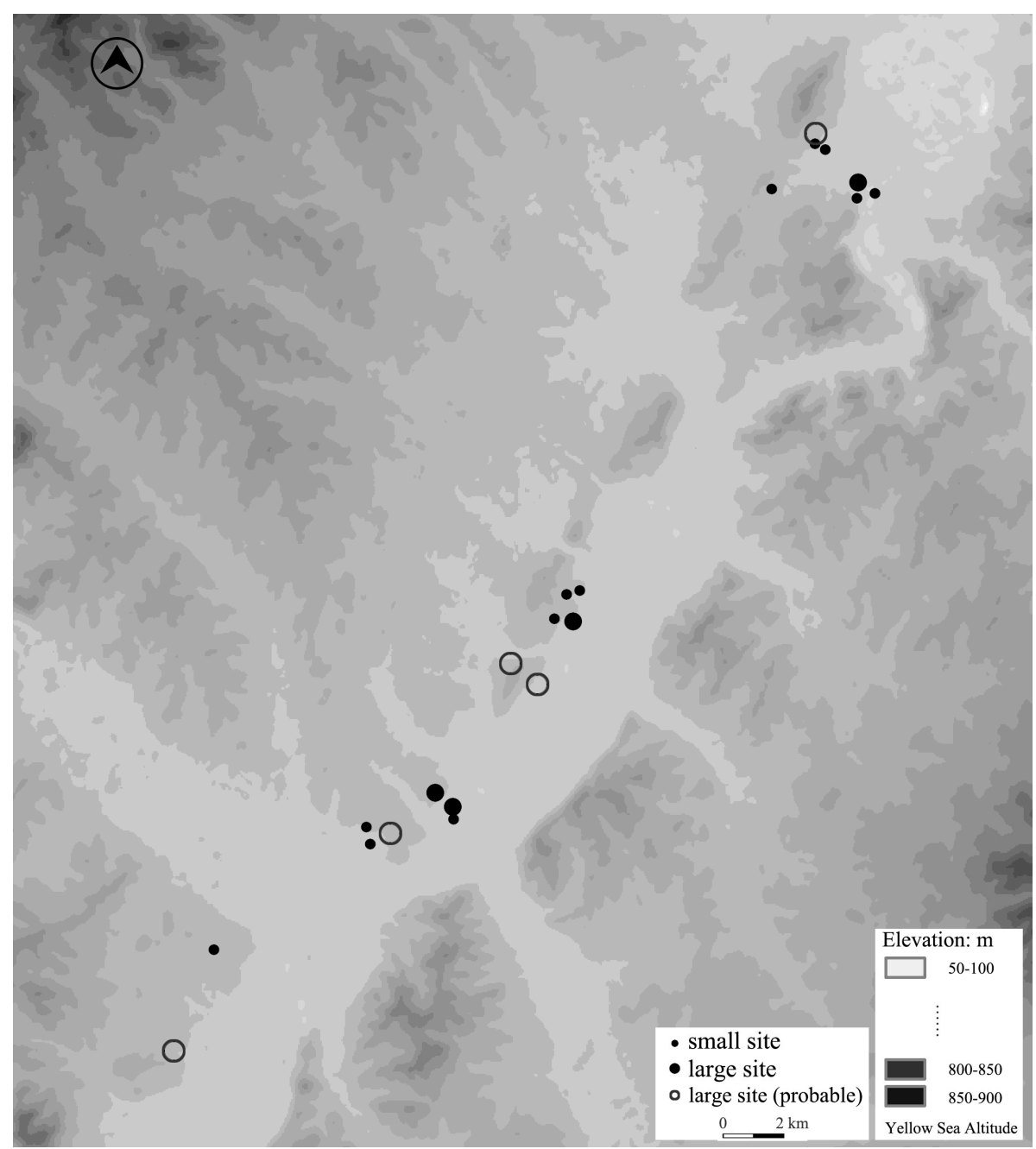

Figure 13: Distribution map of the ceremonial sites at Dongshanzui

\section{Table caption}

\begin{tabular}{|c|c|c|c|c|c|c|c|c|c|}
\hline & (Constant) & $\begin{array}{c}\text { Low } \\
\text { Elevation }\end{array}$ & Slope & $\begin{array}{c}\text { South- } \\
\text { east } \\
\text { Aspect }\end{array}$ & $\begin{array}{c}\text { Distance } \\
\text { to River } \\
\text { Crossing }\end{array}$ & $\begin{array}{c}\text { Ridge } \\
\text { Landform }\end{array}$ & $\begin{array}{c}\text { Proximity } \\
\text { to } \\
\text { Gneiss } \\
\text { Bedrock }\end{array}$ & $\begin{array}{c}\text { Mountain } \\
\text { View }\end{array}$ \\
\hline \multirow{2}{*}{ Univariate p-value } & - & 0.026 & 0.001 & 0.048 & 0.000 & 0.004 & 0.000 & 0.004 \\
\hline \multirow{2}{*}{ Model A } & p-value & 0.003 & - & - & 0.003 & 0.004 & 0.018 & 0.002 \\
\cline { 2 - 10 } & Coefficient & -3.998 & - & - & 2.648 & -0.001 & 2.101 & 2.434 & 2.519 \\
\hline \multirow{2}{*}{ Model B } & p-value & 0.416 & - & 0.039 & 0.026 & 0.016 & 0.005 & 0.011 & - \\
\cline { 2 - 10 } & Coefficient & -0.774 & - & -0.122 & 1.682 & -0.001 & 2.451 & 1.876 \\
\hline
\end{tabular}

Table 1: Summary regression results 


\begin{tabular}{|c|c|c|c|c|c|}
\hline & $\begin{array}{c}\text { South-east } \\
\text { Aspect }\end{array}$ & $\begin{array}{c}\text { Distance to } \\
\text { River Crossing }\end{array}$ & $\begin{array}{c}\text { Ridge } \\
\text { Landform }\end{array}$ & $\begin{array}{c}\text { Proximity to } \\
\text { Gneiss } \\
\text { Bedrock }\end{array}$ & Mountain View \\
\hline $\begin{array}{c}\text { South-east } \\
\text { Aspect }\end{array}$ & 1.000 & -0.315 & 0.054 & 0.366 & 0.551 \\
\hline $\begin{array}{c}\text { Distance to } \\
\text { River Crossing }\end{array}$ & -0.358 & 1.000 & -0.056 & -0.108 & -0.315 \\
\hline $\begin{array}{c}\text { Ridge } \\
\text { Landform }\end{array}$ & 0.054 & -0.056 & 1.000 & 0.350 & 0.044 \\
\hline $\begin{array}{c}\text { Proximity to } \\
\text { Gneiss } \\
\text { Bedrock }\end{array}$ & 0.366 & -0.108 & 0.350 & 1.000 & 0.182 \\
\hline Mountain View & 0.551 & -0.315 & 0.044 & 0.182 & 1.000 \\
\hline
\end{tabular}

Table 2: Correlation matrix for model covariates

\begin{tabular}{|c|c|c|c|c|c|c|c|c|c|c|c|c|c|c|c|c|}
\hline & from 1 & from2 & from 3 & from 4 & from 5 & from6 & from7 & from8 & from 9 & from 10 & from 11 & from 12 & from 13 & from 14 & from 15 & from 16 \\
\hline 1 & NA & 0 & 0.57 & 0 & 0.72 & 1 & 0.04 & 0 & 0 & 0.73 & 0.07 & 0.86 & 0.83 & 0.9 & 0 & 0.93 \\
\hline 2 & 0 & NA & 0.19 & 0 & 0 & 0 & 0 & 0 & 0.4 & 0 & 0 & 0 & 0 & 0 & 0 & 0 \\
\hline 3 & 0.92 & 0.04 & NA & 0 & 0 & 0 & 0 & 0.86 & 0.83 & 0.03 & 0 & 0.07 & 0 & 0.08 & 0 & 0 \\
\hline 4 & 0 & 0 & 0 & NA & 0.56 & 0.32 & 0.38 & 0 & 0 & 0 & 0 & 0 & 0.16 & 0.8 & 0 & 0 \\
\hline 5 & 0.74 & 0 & 0.04 & 0.25 & NA & 0.17 & 0.47 & 0 & 0 & 0.31 & 0.55 & 0.6 & 0.2 & 0.74 & 0 & 0 \\
\hline 6 & 0.82 & 0 & 0 & 0.01 & 0 & NA & 0.38 & 0 & 0 & 0 & 0 & 0 & 0 & 0.01 & 0 & 0.05 \\
\hline 7 & 0 & 0 & 0 & 0.07 & 0.07 & 0.03 & NA & 0 & 0 & 0.13 & 0.36 & 0.37 & 0.36 & 0.35 & 0 & 0.53 \\
\hline 8 & 0 & 0 & 0.66 & 0 & 0 & 0 & 0 & NA & 0.18 & 0 & 0 & 0 & 0 & 0 & 0 & 0 \\
\hline 9 & 0.02 & 0.23 & 0.55 & 0 & 0 & 0 & 0 & 0.67 & NA & 0 & 0 & 0 & 0 & 0 & 0 & 0 \\
\hline 10 & 1 & 0 & 0.38 & 0 & 0.88 & 0.07 & 0.84 & 0 & 0 & NA & 0 & 0 & 0 & 0.64 & 0 & 0 \\
\hline 11 & 0 & 0 & 0 & 0 & 0.8 & 0.35 & 0.96 & 0 & 0 & 0 & NA & 0.4 & 0 & 0.73 & 0 & 0.47 \\
\hline 12 & 1 & 0 & 0.48 & 0 & 0.97 & 0.41 & 0.97 & 0 & 0 & 0 & 0.62 & NA & 0 & 1 & 0.11 & 0.43 \\
\hline 13 & 0.76 & 0 & 0 & 0.71 & 0.7 & 0.22 & 0.7 & 0 & 0 & 0.04 & 0 & 0.09 & NA & 0.99 & 0.9 & 0.99 \\
\hline 14 & 1 & 0 & 0.7 & 1 & 1 & 0.57 & 0.94 & 0 & 0 & 0.98 & 1 & 1 & 1 & NA & 0.55 & 1 \\
\hline 15 & 0 & 0 & 0 & 0 & 0 & 0 & 0 & 0 & 0 & 0 & 0 & 0 & 0.37 & 0.55 & NA & 0.55 \\
\hline 16 & 1 & 0 & 0 & 0 & 0.02 & 0.64 & 0.97 & 0 & 0 & 0 & 0.97 & 0.94 & 0.99 & 1 & 0.94 & NA \\
\hline
\end{tabular}

Table 3: Visibility network for large sites at Niuheliang 